\title{
ANOPLOD ACTYLUS OPHIUROPHILUS N. SP., A SEA SPIDER ASSOCIATED WITH BRITTLE STARS IN THE SEYCHELLES
}

\author{
JAN H. STOCK \\ Institute of Taxonomic Zoology (Zoölogisch Museum), University of Amsterdam, The Netherlands
}

\begin{abstract}
A new species of Pycnogonida, Anoplodactylus ophiurophilus, is described. It is associated with three species of the genus Ophiocoma in the Seychelles (Indian Ocean) and constitutes the first recorded case of a sea spider found on Ophiuroidea. In comparison with the 83 species actually recognized in Anoplodactylus, the new species shows hardly any morphological adaptations due to this remarkable association.

\section{RESUME}

Une espèce nouvelle de Pycnogonides, Anoplodactylus ophiuropbilus., est décrite. Elle est associé à trois espèces du genre Ophiocoma aux Seychelles (Océan Indien), le premier cas connu d'un Pycnogonide rencontré sur des Ophiures. En comparaison avec les 83 espèces reconnues dans le genre Anoplodactylus, l'espèce nouvelle ne montre guère d'adaptations morphologiques relatives à cette association remarquable.
\end{abstract}

\section{INTRODUCTION}

To Dr. N. A. Sloan, Queen Mary College, University of London, I $\mathrm{am}$ indebted for entrusting me with a number of small pycnogonids found in remarkable abundance clinging to the ventral (oral) side of the arms of ophiuroids of the genus Opbiocoma in the Seychelles (Indian Ocean). Ophiocoma doederleini De Loriol, 1899, had the highest incidence of pycnogonid associates; lower infestation rates were found on $O$. erinaceus Müller \& Troschel, 1842 and $O$. pica Müller \& Troschel, 1842 (see Sloan, in preparation, for detailed data on infestation rates and the nature of the association). The pycnogonid proved to be a new species of the large genus Anoplodactylus which will be described in the sequel.

\section{Anoplodactylus ophiurophilus n. sp.}

(Figs. 1-9)

Material examined: One ovigerous $\hat{\delta}$ (holotype), 1 (allo. type); 10 ovigerous $\hat{\delta} \hat{\delta}, 3 \hat{\delta} \hat{\delta}, 15 \& \uparrow$ (paratypes). Aldabra atoll, Seychelles $\left(09^{\circ} 24^{\prime} \mathrm{S} 46^{\circ} 20^{\prime} \mathrm{E}\right)$, in very shallow waters (eu- and sublittoral), Feb. 25, 1978. Associated with the ophiuroid Ophiocoma doederleini De Loriol, 1899 (Zoö. logisch Museum Amsterdam coll. no. Pa. 2841-42).

\section{Description}

Male: Trunk with indistinct segmentation lines on the dorsal surface, more distinct ones on the ventral side. Neck short, expanded in front of the first lateral processes. Lateral processes touching in their basal part, separated distally; distodorsally armed with two or three small spines. Ocular tubercle low, directed anteriad, rounded, eyes not visible at least in preserved material; lateral sense organs present as small processes on the lateral surface of the ocular tubercle, in subterminal position. Abdomen about as long as the fourth lateral processes, directed upward at an angle of some $35^{\circ}$. The entire trunk, including the ocular tubercle, the lateral processes and the abdomen, covered with a short pubescence.

Proboscis straight, almost cylindrical, slightly wider subterminally (type $\mathrm{B}^{\prime \prime \prime}$ to $\mathrm{D}^{\prime \prime}$, according to the classification of Fry \& Hedgpeth, 1969: 2021).

Chelifore scape pubescent, chela almost as long as scape. Palm with some spinules; immovable finger shorter than the palm, strongly curved, armed with two small denticles; movable finger longer than the palm, less curved, armed with a spinule and some very small denticles.

No trace of palps. Oviger 6-segmented; relative lengths of the segments $14,22,25,17,16$ and $6 \%$ (total: $100 \%$ ). Reversed spines are numerous on segment 5. Segment 6 triangular, small. Eggs on oviger small (diameter $44-53 \mu \mathrm{m}$ ) and very numerous.

Like the trunk, the legs are covered with short setules. No genital spur. Sexual apertures found with certainty only on coxa 2 of leg 4. Femur with a single, short cement gland duct, just in 


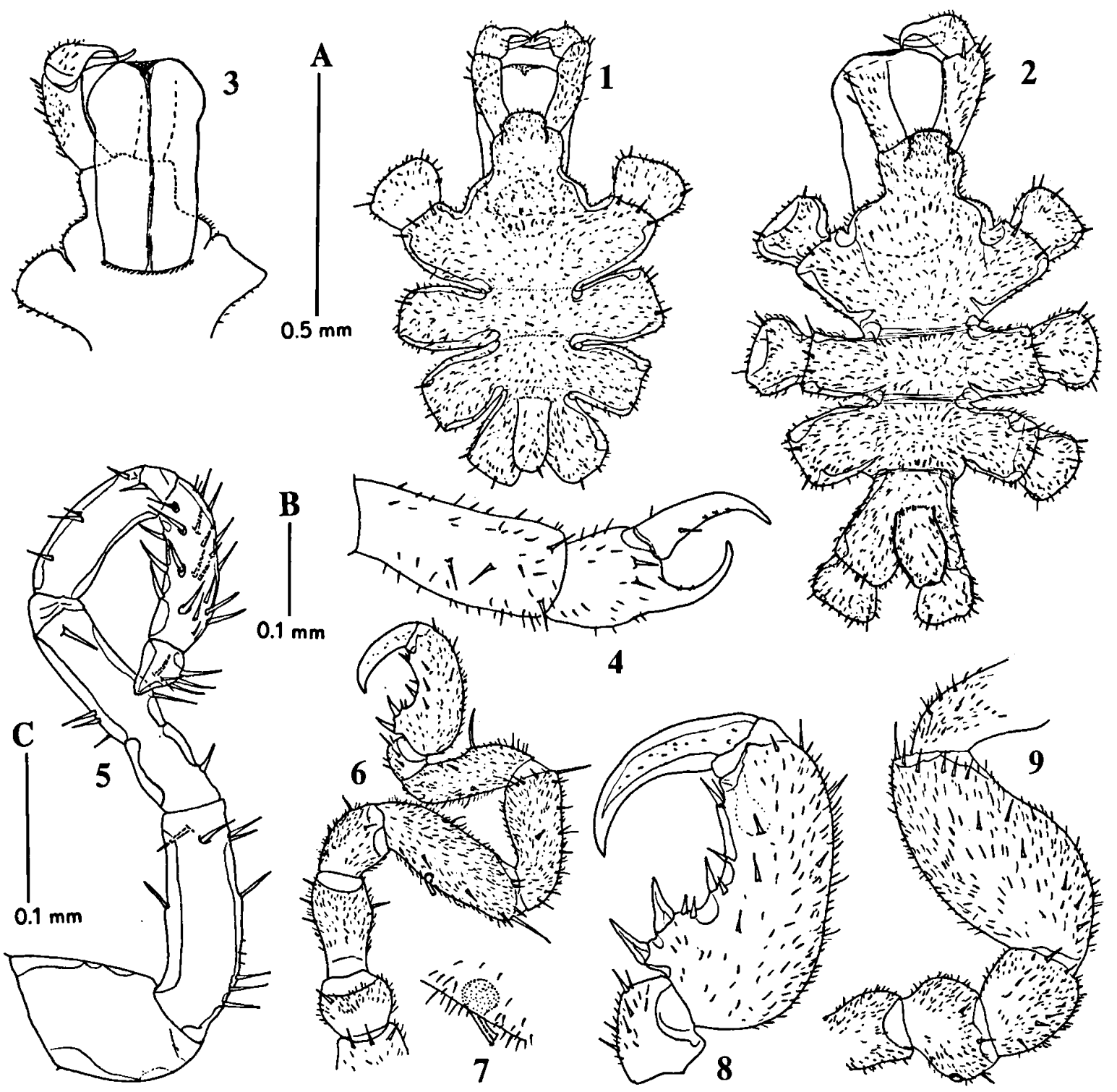

Figs. 1-9. Anoplodactylus opbiurophilus n. sp., paratypes: 1, trunk, ô, dorsal (scale A); 2, trunk, $\$$, dorsal (A); 3 , anterior part of the body, $\$$, ventral $(A) ; 4$, chelifore, $\hat{\delta}(B) ; 5$, oviger, $\hat{\delta}(B) ; 6$, third leg, $\hat{\delta}(A)$; 7 , cement gland aperture, $\hat{\delta}(C) ; 8$, distal segments of third leg, $\hat{\delta}(B) ; 9$, basal segments of third leg, $\uparrow(A)$.

front of the middle of the segment, on its dorsal surface. Femur the longest, tibia 2 the shortest of the longer leg segments. Tarsus of normal shape (not wedge-shaped). Propodus with a very strong heel, armed with two heavy spines; sole with two basal and two distal spines, but without the usual row of regular spinules and without a lamina. Claw strong, curved, without any trace of auxiliary claws.
Female: Trunk more slender; lateral processes slightly more widely separated; segmentation lines more distinct, also on the dorsal surface of the trunk. Proboscis as in male, thus without ventral outgrowths. No palps, no ovigers. Sexual apertures on coxa 2 of all legs; no genital spur. Femur strongly swollen. Otherwise, the morphology is similar to that of the male. 
Measurements of two paratypes, in $\mathrm{mm}$

Length cephalic somite (from tip of ocular tubercle)

Length second trunk somite

Length third trunk somite

Length fourth trunk somite (to tip of fourth lateral processes)

Length abdomen

Width across second lateral processes

Length proboscis (ventral)

Greatest width proboscis

Third leg - coxa 1

coxa 2

coxa 3

femur

tibia 1

tibia 2

tarsus

propodus

claw

$$
\text { ô }
$$

$0.41 \quad 0.51$

0.120 .16

0.110 .17

$0.23 \quad 0.24$

$0.17 \quad 0.18$

$\begin{array}{ll}0.60 & 0.61\end{array}$

$0.46 \quad 0.53$

$\begin{array}{ll}0.24 & 0.29\end{array}$

$\begin{array}{ll}0.16 & 0.19\end{array}$

$\begin{array}{ll}0.23 & 0.22\end{array}$

$\begin{array}{ll}0.17 & 0.24\end{array}$

$\begin{array}{ll}0.38 & 0.59\end{array}$

$0.30 \quad 0.44$

$0.29 \quad 0.40$

0.060 .11

$0.28 \quad 0.36$

$0.17 \quad 0.25$

Distinction from other species

I recognize, at least provisionally, 83 valid species in the genus Anoplodactylus, which are listed in alphabetical sequence below. Also enumerated are the species requirenda, as well as a number of taxa that are at present considered synonyms, homonyms or alternative spellings.

1 aculeatus Möbius, 1902

2. anartbrus Loman, 1908

3. angulatus (Dohrn, 1881) (ex Phoxicbilidium)

4. aragaoi Sawaya, 1950

5. arcuatus Child, 1977

6. arescus Marcus, 1959

7. arnaudae Stock, 1978

8. australis (Hodgson, 1914) (ex Pboxichilidium)

9. bahamensis Child, 1977

10. batangensis (Helfer, 1938) (ex Pycnosoma)

11. brasiliensis Hedgpeth, 1948 (pro A. pygmaeus Marcus, 1940, non Hodge, 1864)

12. brevicollis Loman, 1908

13. californicus Hall, 1912

14. capensis (Flynn, 1928) (ex Phoxichilidium)

15. compactus Hilton, 1939

16. coxalis Stock, 1968

17. cribellatus Calman, 1923

18. n. sp. Stock, in press (pro A. virescens Arnaud, 1974, non Hodge, 1864)

19. derjugini Losina-Losinsky, 1929

20. digitatus (Böhm, 1879) (ex Phoxichilidium)

21. erectus Cole, 1904

22. eroticus Stock, 1968

23. evansi Clark, 1963

24. evelinae Marcus, 1940

25. gestiens (Ortmann, 1890) (ex Phoxicbilidium)

26. glandulifer Stock, 1954

27. guyanensis Child, 1977

28. baswelli (Flynn, 1918) (ex Halosoma)

29. bokkaidoensis (Utinomi, 1954) (ex Phoxichilidium)
30. inermis Losina-Losinsky, 1961

31. insigniformis Stock, 1975

32. insignis (Hoek, 1881) (ex Pboxicbilidium)

33. iuleus Stock, 1975

34. jonesi Child, 1974

35. jungersi Fage, 1949

36. laminifer Arnaud, 1974

37. lentus Wilson, 1878

38. longiceps Stock, 1951 (pro A. longicollis Williams, 1941, preoccupied)

39. longiformis Child, 1977

40. mamillosus Stock, 1954

41. marcusi (de Mello-Leitão, 1949) (ex Halosoma)

42. maritimus Hodgson, 1914

43. massiliensis Bouvier, 1916

44. massiliformis Stock, 1975

45. micros Bourdillon, 1955

46. minusculus Clark, 1970

47. minutissimus Stock, 1954

48. n. sp. Stock, in press (pro A. robustus Stock, 1954, 1955, 1975, non Dohrn, 1881)

49. multiclavus Child, 1977

50. neglectus Hoek, 1898

51. nodosus Hilton, 1939

52. oculatus Carpenter, 1905

53. oculospinus Hilton, 1942

54. pacificus Hilton, 1942

55. pectinus Hedgpeth, 1948

56. pelagicus Flynn, 1928

57. petiolatus (Krøyer, 1844) (ex Phoxichilidium)

58. pharus Stock, 1975

59. polignaci Bouvier, 1914

60. portus Calman, 1927

61. pulcher Carpenter, 1907

62. pycnosoma (Helfer, 1938) (ex Peritrachia)

63. pygmaeus (Hodge, 1864) (ex Pallene)

64. quadratispinosus Hedgpeth, 1943

65. robustus (Dohrn, 1881) (ex Phoxichilidium)

66. simplex Clark, 1963

67. simulator Stock, 1975

68. spinosus (Losina-Losinsky, 1961) (ex Phoxicbilidium)

69. squalidus Clark, 1973

70. stictus Sawaya, 1945

71. stocki Bācescu, 1959

72. tarsalis Stock, 1968

73. toros Child \& Hedgpeth, 1971

74. trispinosus Stock, 1951

75. tubiferus (Haswell, 1884) (ex Phoxicbilidium)

76. turbidus Stock, 1975

77. typhlops Sars, 1888

78. unilobus Stock, 1959

79. unospinus Hilton, 1942

80. versluysi Loman, 1908

81. virescens (Hodge, 1864) (ex Phoxichilidium)

82. viridintestinalis (Cole, 1904) (ex Halosoma)

83. xenus nom. nov. (pro A. haswelli Stock, 1954, non Flynn, 1918, see Clark, 1963: 49)

Species inquirenda, homonyms, synonyms, alternative names: angulirostris (Dohrn, 1881: 34, 35, 68), nom. alt. pro $A$. angulatus (Dohrn, 1881).

antillianus Stock, 1975, jun. syn. of A. jonesi Child, 1974. carvalboi Marcus, 1940, jun. syn. of A. portus Calman, 1927. 
exiguus (Dohrn, 1881) (ex Pboxicbilidium), jun. syn. of A. pygmaeus (Hodge, 1864).

bedgpetbi Băcescu, 1959 (as $A$. petiolatus bedgpethi), species inquirenda aff. guyanensis Child, 1977.

insignis bermudensis Cole, 1904 (identical with insignis s. str.).

intermedius Hilton, 1942, jun. syn. of A. batangensis (Helfer, 1938).

investigatoris Calman, 1923, jun. syn. of A. digitatus (Böhm, 1879).

lappa (Böhm, 1879) (ex Pallene), species inquirenda.

longicollis (Dohrn, 1881), jun. syn. of A. petiolatus (Krøyer, 1844).

longicollis Williams, 1941, homonym of longicollis (Dohrn, 1881); now: A. longiceps Stock, 1951.

longirostris (Dohrn, 1881: 34), nom. alt. pro longicollis (Dohrn, 1881).

maritimus sensu Hedgpeth, 1948 (non Hodgson, 1914) = A. iuleus Stock, 1975.

mutilatus (Frey \& Leuckart, 1847) (ex Pboxichilidium), species inquirenda.

partus Giltay, 1934, jun. syn. of A. maritimus Hodgson, 1914.

parvus (Hilton, 1939) (ex Phoxichilidium), homonym of parvus Giltay, 1934; now: $A$. bokkaidoensis (Utinomi, 1954).

plumulariae (Von Lendenfeld, 1883) (ex Pboxicbilidium), species inquirenda.

projectus Hilton, 1942, jun. syn. of $A$. portus Calman, 1927. robustus Hilton, 1939, homonym of $A$. robustus (Dohrn, 1881 ); jun. syn. of $A$. portus Calman, 1927.

robustus Zilberberg, 1963 (non Dohrn, 1881); cf. A. marcusi (de Mello-Leitão, 1949).

saxatilis Calman, 1923, jun. syn. of $A$. digitatus (Böhm, 1879).

spinosus Möbius, 1902; transferred to Parapallene.

stylirostris Hedgpeth, 1948, jun. syn. of $A$. batangensis (Helfer, 1938).

stylops Loman, 1908, jun. syn. of $A$. pulcher Carpenter, 1907. tenuirostris Lebour, 1948, jun. syn. of A. batangensis (Helfer, 1938).

Of the 83 species enumerated above, the following 14 differ from $A$. opbiuropbilus n. sp. in having the femoral cement glands $(\hat{o})$ discharging through more than one aperture on each leg: angulatus, australis, cribellatus, "n. sp. no. 18", glandulifer, hokkaidoensis, longiceps, longiformis, multiclavus, oculatus, pycnosoma, robustus, virescens and xenus (the condition of the cement gland is unknown for 15 species, e.g. because the male of those species is unknown).

Another 9 species have a single cribriform or pore-like cement gland aperture $(\hat{\partial})$, at any rate not a duct-like one as in the new species described above: compactus, evelinae, insignis, lentus, massiliensis, "n. sp. no. 48", pectinus, polignaci, virid- intestinalis (here again, the condition of the cement gland aperture is unknown in the same 15 species as in the preceding paragraph).

The 37 species listed below differ from $A$. ophiurophilus n. sp. in possessing a distinct propodal lamina $(\mathcal{q}, \hat{\delta})$ : aragaoi, arcuatus, arescus, arnaudae, babamensis, brasiliensis, compactus, cribellatus, digitatus, erectus, gestiens, glandulifer, guyanensis, iuleus, jonesi, jungersi, laminifer, longiformis, mamillosus, maritimus, micros, minusculus, minutissimus, multiclavus, nodosus, oculospinus, pacificus, petiolatus, pharus, pygmaeus, stictus, stocki, tarsalis, toros, trispinosus, turbidus, viridintestinalis (the condition of the propodal armature is unknown for one species).

One species, batangensis, has a styliform proboscis $(q, \delta)$ of a shape quite unlike that of the present new species (the shape of the proboscis is known for all 83 species listed above).

The following 11 species are known to possess ventral outgrowths on the $q$ proboscis, whereas the presently described species is devoid of such outgrowths: arnaudae, brevicollis, digitatus, evansi, insignis, jungersi, polignaci, portus, stictus, unilobus, versluysi (the condition of the 9 proboscis is unknown for 19 species, e.g. because the female sex is unknown).

Most species of the genus, viz. 75, possess rudimentary auxiliary claws. Only eight species are devoid of auxiliaries, a condition shared by $A$. ophiuropbilus n. sp. These eight species are: aculeatus, anarthrus, arescus, batangensis, pectinus, pygmaeus, stictus, and tarsalis.

The above comparisons show that only two species of Anoplodactylus share the six character states used in the preceding lines with $A$. ophiurophilus n. sp., viz. $A$. aculeatus and $A$. anarthrus. The former of these two, aculeatus, does not resemble in the least the new species, since it possesses long spurs on the coxae, femur and first tibia, has chelae with closing (as opposed to gaping) fingers, and carries a regular row of spinules on the propodal sole (in fact, $A$. aculeatus is very close to, if not identical with, $A$. insignis). The second of the two species, anartbrus, is more similar to $A$. opbiuropbilus n. sp., but possesses a row of six regular spinules of a size on the pro- 
podal sole, and has touching (as opposed to separated) lateral processes.

It is clear, therefore, that the material from the Seychelles represents an undescribed species, which I propose to call $A$. ophiurophilus in virtue of its unique association with ophiurans of the genus opbiocoma. It is remarkable, though, that the pycnogonid has developed so few morphological adaptations to its peculiar mode of life. As point of fact, the new species could almost be considered a generalized Anoplodactylus without any striking characters. The only, however slight, adaptation might be found in the morphology of the propodus, which is strongly curved, lacking the usual row of sole spines, and forming with the opposing claw a strongly prehensile device.

Up to now not a single pycnogonid was known to be associated with ophiuroids, although other echinoderm groups are reported as possible food source (Holothuroidea, Echinoidea; refs. in Stock, 1978). Members of the genus Anoplodactylus have been recorded mainly from different groups of hydroids (refs. in King, 1973, tables III \& IV) and medusae, but the closely related genus Pycnosoma was recorded from the echinoderm Strongylocentrotus, a sea urchin, by Losina-Losinsky, 1933. Anoplodactylus is predominantly a warm-water genus, with only few representatives in temperate (e.g. A. petiolatus), cool (e.g. A. laminifer) or polar (e.g. A. australis) waters. Several representatives of the genus have been found, however, in cooler deep waters (e.g. $A$. arnaudae, $A$. oculatus) There is no doubt that the genus reaches its greatest proliferation in the tropics of both the Indo-Pacific and the Caribbean.

\section{REFERENCES}

(A complete bibliography of the Pycnogonida can be found in Fry \& Stock, 1978).

FRY, W. G. \& J. W. HedGPETH, 1969. The fauna of the Ross Sea, 7. Pycnogonida, 1. Colossendeidae, Pycnogonidae, Endeidae, Ammotheidae. Mem. N.Z. oceanogr. Inst., 49 (= Bull. N.Z. Dep. scient. ind. Res., 198): $1-139$.

FRY, W. G. \& J. H. STOCK, 1978. A pycnogonid bibliography. Zool. J. Linn. Soc. Lond., 63 (1/2): 197-238.

KING, P. E., 1973. Pycnogonids: 1-144 (Hutchinson, London).

Losina-Losinsky, L. K., 1933. Die Pantopoden der östlichen Meere der U.S.S.R. Issled. Morei S.S.S.R., 17: 43-80.

SLOAN, N. A., in preparation. An interesting pycnogonidophiuroid association. Mar. Biol.

STock, J. H., 1978. Experiments on food preferences and chemical sense in Pycnogonida. Zool. J. Linn. Soc. Lond., $63(1 / 2): 59.74$.

- in press. Pycnogonida from the mediolittoral and infralittoral zones in the tropical western Atlantic. Stud. Fauna Curaçao. 